\title{
Meaning of "employee happiness" within the context of complex organisations? An explanatory review on the UAE labour force
}

\section{Vic Benuyenah}

School of Business Economics and Informatics, Birkbeck College, London, UK and Department of Business, Dubai Women's College, Dubai, United Arab Emirates, and

Bharti Pandya

Department of Business, Dubai Women's College, Dubai, United Arab Emirates
Meaning of "employee happiness"

Received 4 April 2020 Revised 26 May 2020 Accepted 22 June 2020

\begin{abstract}
Purpose - In this study, the authors build on the current frameworks of happiness provided by the PERMA model, the World Happiness Report Index and the theoretical framework provided by the proponents of jobsatisfaction model, motivation, employee engagement and commitment. The authors argue that, the existing theoretical framework in the management and the HR literature are just different aspects of a common goal happiness. This position is consistent with the overall happiness projects championed by governments across the world, including the UK, Bhutan, several Scandinavian nations and essentially the United Arab Emirates. A chasm that currently exists in the literature is the availability of a universally acceptable definition for happiness and protocols for measuring happiness. The authors conclude that more research is required to keep pace with industry development relating to employee happiness initiatives.
\end{abstract}

Design/methodology/approach - Using quasi-literature review, the authors analysed selected studies on the theory of happiness to identify how each have treated the concept of happiness in organisations.

Findings - It is erroneous to promote national or international happiness initiatives without starting from the micro level - in this case, the institutions of society should start measuring happiness from the micro level to help understand what happiness actually means.

Research limitations/implications - As an opinion piece, its recommendations need to be applied cautiously.

Originality/value - Till date, only a few studies have explored the concept of happiness from microorganisational level.

Keywords Workplace happiness, Complex organisations

Paper type Viewpoint

\section{Introduction}

Happiness from communitarian point of view provides satisfaction to all stakeholders in a society (Veenhoven, 2009); therefore, it is virtuous that organisations strive to craft

(C) Vic Benuyenah and Bharti Pandya. Published in Rajagiri Management Journal. Published by Emerald Publishing Limited. This article is published under the Creative Commons Attribution (CC BY 4.0) license. Anyone may reproduce, distribute, translate and create derivative works of this article (for both commercial and non-commercial purposes), subject to full attribution to the original publication and authors. The full terms of this license may be seen at http://creativecommons.org/ licences/by/4.0/legalcode

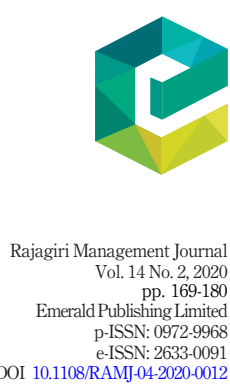


RAMJ

14,2

strategies that will make their workers happy, at least in principle. The problem however is not so much with initiatives that promote happiness, as there are several of them; rather, the issue lies with what employees perceive as happiness and what employers on the other hand perceive as employee happiness. Undoubtedly, a confusion arising from different definitions can affect the metrics and standards used in measuring happiness and the attempts made to promote or seek it can be problematic in organisations in the UAE.

Though it is easy to identify and deal with other metrics that impact on organisational success, it is much more a challenge to identify any management factor that influences employee happiness without adopting a somewhat phenomenological approach to exploring these factors; phenomenological approach tends to help in understanding the deeper experiences of individuals (Smith, 2010; Eatough and Smith, 2010), if an empirical standpoint is adopted. Consequently, unlike, financial metrics that are easily adjustable when targeting specific organisational objectives (Cascio, 2012; Thorne, 2000), a logical way to deal with happiness is to allow a personal interpretative analysis to determine the happiness parameters among employees - after all, one person's happiness is likely to be different from another person's. For financial metrics just like other non-human assets, it is possible to subject them to a scientific predictive analysis that allows managers to make accurate decisions - this is not the case with happiness. This paper attempts to explain what really is meant by employee happiness within organisations that have high employee diversity, fast-pace of work, convoluted work and information technology (IT) infrastructural systems, particularly in the UAE. As an explanatory study, the paper makes recommendations for micro-data capturing in organisations to enable a more accurate measure of national happiness.

\section{Methodology}

This study draws on both the strengths of case study and critical review. We observed the current happiness initiatives in the UAE and conducted a review of a sample of selected happiness literature and framework while placing emphasis on articles that have featured mainly in EmeraldInsight repository of management journals within the past ten years. A key word search for the word combinations (happiness + organisations) and (employee + happiness) was conducted to satisfy the inclusion criterion. The criterion returned 19,232 and 15,726 results, respectively, which was rather too large and mainly irrelevant to this study; for example, one journal article found in the results was titled "Food and happiness" whereas several of the results featured articles in fields other than management. In line with Petticrew and Roberts (2008), who state that: "the aim of a literature search is not to retrieve everything, but to retrieve everything of relevance while leaving behind the irrelevant", we eschewed all the irrelevant articles and focussed on the ten most relevant ones. The articles were then vetted for their treatment of the subject of happiness within the organisation and how they specifically define the term with reference to organisations' employees. Manual annotation of evidence of the use of the term happiness was made on the right hand of the text page whereas the lefthand side was used to identify the details of the implications of the themes. This approach is in line with the hermeneutic philosophy popularised by the Husserlian and the Heideggerian schools of thought that emphasise that we follow the hermeneutic cycles in identifying patterns in the text being explored. As this is more common with empirical studies, we implement the method cautiously by excluding the element of "phenomenology" from the analysis, mainly because it is impossible to explore this using a quasi-literature review.

\section{Framing happiness in the context of complex organisations}

The recent view expressed by a number of management theorist (Lawrie et al., 2016; Mikkelsen and Clegg, 2017; Powell and Tilt, 2017) is that today's organisational complexity be framed 
beyond what traditional organisational structures purported it to be. With this in mind, the level of complexity characterising an organisation has to depend on a number of factors including the definition of strategy, employee task definition and compliance and monitoring or from HR perspective, the degree of multiculturalism and role set of employees. The consensus gathered from the current literature sources sampled from the HR domain is that, the definition of task is the determinant of organisational complexity (Cooksey, 2003; Critten, 2016; Lawrie et al., 2016). Similarly, Mullins (2010) has associated complexity with reorganisation of work including, information technology and employee networks, particularly after the Scientific era. As Mullin's view on complex organisations excludes the cross cultural element often cited by cultural experts (Humphries and Whelan, 2017), we conclude that a more relevant and concurrent definition of complex organisations will be relevant for this study - thus: "organisations that are characterized by high degrees of cross cultural and diverse employee systems, IT and financial systems as well as diverse human cognitive and affective dispositions". In harmony with our definition therefore, most organisations in the UAE are likely to be seen as complex as the workforce is highly diversified in terms of cultures, languages, religions, race, family structures and to some extent management's philosophy in managing such diverse systems. Evidently, more than $86 \%$ of UAE's population is composed of expatriates from all over the world, setting UAE's organisations as highly complex organisations (The World Bank, 2018). Considering the complexity, the UAE labour force presents a research opportunity to evaluate how happiness is currently framed within organisations operating in the country. The question that arises immediately is, how can happiness be defined to incorporate the values, cultures, personal and national background of employees in such organisations found in the UAE labour market? The closest organisational definition of happiness is provided by Lambert et al. (2002, p.117) who define job satisfaction as "a subjective, individual-level feeling reflecting whether a person's needs are or are not being met by a particular job". It is worth observing that even this definition fails to be specific leading us to provide a working definition as:

Employee happiness includes, workers disposition towards accepting working conditions as satisfactory, whilst demonstrating high levels of agreeableness, cooperation and motivation to their task, employer, colleagues and other stakeholders in a manner that is directly evident by the employee himself or herself

\section{Importance of happiness to the labour force in the UAE}

Detailed examination of complex organisations (Mullins, 2010) reveals that both individuals and organisations desire to achieve happiness at all levels of society. In spite of this zeal, the management literature and "happiness consultants" alike have failed to agree on a common definition (Veenhoven, 2009). Such disagreement on a common definition can potentially affect initiatives drawn up by counties such as the UAE and others seeking to make happiness a key target. Although the term continues to be misdefined, misapplied and often confused with other concepts at both the global and organisational levels, in the organisational context, happiness has been incorporated with and measured within other management framework such as, motivation (Bassett-Jones and Lloyd, 2005; Burdbar Khan and Nisar Sheikh, 2012), job satisfaction (Baddah, 2016; Salas-Vallina et al., 2017) and employee engagement (Attridge, 2009; Kumar and Pansari, 2015; Rahman et al., 2017). A crucial central point to gauge employee happiness is the perception of the individual reporting the level of their happiness, as the phenomenon of happiness is almost impossible to generalise scientifically. In many cases, the level of happiness and the factors leading to the individual's state of happiness can vary greatly across different cultures and
Meaning of
"employee
happiness" 
RAMJ

14,2

172

organisational climate, context and the individual's disposition towards and interpretation of happiness. A number of models such as PERMA (Seligman, 2011) and gross national happiness $(\mathrm{GNH})$ have approached the concept of happiness from a scientific perspective often leaving a gap between what is measured and what is experienced. Though we all desire a high level of happiness, the measurement of the concept has proven elusive, as scholars fail to agree on a single definition or measurement. To make progress in the study of happiness, therefore, requires first and foremost, an understanding of happiness and how it can be measured correctly by organisations and the UAE Government. In this research, an attempt is made to understand what happiness is, how employees cognitively experience it and how its measurement in the UAE can be improved. UAE, being a young country strives to be amongst the Top 5 happiest countries by 2021 and is amongst the few nations to establish a separate ministry dedicated to the nation's happiness and well-being (Happiness Agenda, 2018). We can therefore estimate that the need to make employees happy in the labour force or in the organisations operating in the UAE is continuing to be essential to the country and its people.

\section{Misconceptions of happiness concepts}

The generalisability of much published research on the concept of happiness is problematic, as each writer (including us) would approach the subject from a subjective angle. Being a vague term and almost impossible to fully comprehend, lexicographers have agreed on common features that guide our understanding of the concept of happiness. For example, the Merriam-Webster Dictionary defines happiness in two ways; "a state of well-being and contentment" or "a pleasurable or satisfying experience". The concept of well-being seems quite a broad construct and may cover several factors in and outside of the organisational landscape, whereas contentment may be seen as a static concept relating to the individual's satisfaction. Within the context of this research, all the definitions sampled from the various dictionaries may be questionable (Table 1), as they refer to "pleasure", which is not often consistent with the organisational view of a happy workforce and certainly not a term UAE would use in measuring happiness. Pleasure may derive from non-work related activities or experiences that may not be managed by external forces, for example, managers. Individual satisfaction, on the other hand, can be a valid way to frame the concept of happiness (Horwitz, 2017; Solansky et al., 2014) - for example, we can ask people to report on their level of satisfaction, which can relate directly to their level of happiness about a particular work activity or method or managerial decision or style. Earlier attempts to define happiness in

\begin{tabular}{lll}
\hline Source & Happiness & Happy \\
\hline Cambridge Dictionary & & $\begin{array}{l}\text { feeling, showing } \\
\text { or causing pleasure or satisfaction }\end{array}$ \\
$\begin{array}{l}\text { Merriam-Webster } \\
\text { Dictionary }\end{array}$ & $\begin{array}{l}\text { a state of well-being and contentment" OR } \\
\text { "axford Learners } \\
\text { the state of feeling or showing pleasure OR } \\
\text { Dictionary }\end{array}$ & $\begin{array}{l}\text { the state of being satisfied that something is } \\
\text { good or right }\end{array}$ \\
$\begin{array}{l}\text { Good fortune or good luck in life generally } \\
\text { or in a particular affair; success, prosperity }\end{array}$ \\
$\begin{array}{l}\text { OR The The state of pleasurable contentment of } \\
\text { mind; deep pleasure in or contentment with } \\
\text { one's circumstances }\end{array}$
\end{tabular}

Table 1.

Dictionary

definitions of

happiness a state of well-being and contentment" OR

"a pleasurable or satisfying experience good or right mind; deep pleasure in or contentment with one's circumstances 
terms of wealth or level of income has been debunked by studies carried out about a decade ago (Tella and MacCulloch, 2006). Tella and MacCulloch (2006) pointed out that if it was possible to measure happiness by watching what people do (an economics perspective) rather than measuring what people say, the concept of happiness would be much better understood and perhaps, defined. Unfortunately, it is very difficult to define the term thereby leaving us to resort to definitions provided in lexicons (Table 1) as such definitions are convenient to people seeking a firsthand interpretation of the concept.

The discussion thus far suggests that, definitions of happiness create more confusion than clarity. Similar confusion in understanding and expression of happiness has been studied by Delle Fave et al. (2016). Having reviewed over 7,500 happiness definitions provided by participants from 12 countries Delle Fave et al.(2016) found that the understanding of happiness varies based on the country, religion, age, gender, marital status and similar socio-cultural factors. Because of these predictors, happiness has been viewed to be related to either health or psychological well-being or religion or community relation. These factors may in fact, correlate with variables identified earlier for complex organisations represented by high degrees of cultural and socially diverse employees.

\section{Happiness theories and their prevailing gaps}

Unlike within the field of psychology, management scientists are yet to focus more on the subject of happiness in the workplace (Benuyenah and Pandya, 2020). As a concept in work studies, happiness itself has not been explored or promoted independently as an antecedent of performance although nationally, the concept has received somewhat extensive interest, particularly in the works of Veenhoven (2009) and internationally, in the reports produced by United Nations (2013). Scholarly work in the field of "organisational happiness" has focussed on terms other than "happiness" for nearly a century (Maslow, 1954; Herzberg, 1959; McClelland, 1984) suggesting that the concept of happiness has either been taken for granted or has not fully been accepted as a core part of organisational theory (Okulicz-Kozaryn, 2016). For example, Okulicz-Kozaryn (2016) noted that a search for the word "happiness" in two leading journals in public policy and administration/management had no results although several activists, and in fact economist, are eagerly pushing for institutions to accept and promote the concept of happiness. This research gap might suggest that previous studies were actually exploring the same concept of happiness, although their approach and concepts may look different; we are tempted to ask the question, is the overall organisational goal of motivation, satisfaction and well-being, after all, about happiness and consequently a philosophical quagmire?

In spite of the traditional confusion, some popular writers on motivation theory (Maslow, 1954; Herzberg, 1959), especially on the element of content theories of motivation, might be working towards a common goal - what exactly motivates workers (Mullins, 2010)? Similarly, the purpose of process theories which looks at how employees can be motivated has formed the core of the works by Adam (1965) and Vroom (1964), who both worked in the 1960s hoping to find a panacea to organisational motivation (happiness). Though the aim of this paper is not to chronicle a list of motivation theories, it is worth noting that the attempts made to understand what exactly makes employees "happy" should be seen as integral part of scholarly work in the field of motivation and job satisfaction. It is therefore erroneous to promote national or international happiness initiatives without starting from the micro level - in this case, the institutions of society including, commercial and government organisations in the UAE.

If we now turn to the other theoretical constructs that are formulated and often correlated with performance, the list is almost unending despite the majority of them being difficult to measure. For example, employee engagement has extensively being investigated (Anitha, 2014; Fisher, 2010; Jiao et al., 2011; Mangai and De Vries, 2018) although its measure is still
Meaning of
"employee
happiness"

173 
RAMJ

14,2

controversial; loyalty and commitment (Dong and Liu, 2010; Jassawalla et al., 2004) may have implications for happiness, yet we are not able to formulate a clear measurement tool for them. Perhaps we can argue that, most constructs that have a psycho-social dimension are very difficult to measure and happiness is just one of them, as its experience and expression varies from person to person.

\section{Measurement frameworks of happiness and their weaknesses}

Just like the academic constructs, definitions of happiness at the global level equally suffer from lack of convergence in terms of measurement instruments (Benuyenah and Pandya, 2020). Although a full assessment of all global models on happiness is beyond the scope of this paper, nevertheless, it is important to frame the concepts of employee happiness within the wider context of the models discussed further. For nearly half a century, Bhutan has been applying GNH Index to measure country growth and development (Parackal, 2016; Sithey et al., 2015) and denounced the global measures such as gross national product (GNP) and gross domestic product (GDP). Jigme Singye Wangchuck, the King of Bhutan and the Ignitor of GNH, argued in 1972 that measures such as GNP and GDP do not measure the social well-being. Elaborating further, Dixon (2006) pointed out that GNP does not account for services provided to "enhance social well-being, degradation of critical assets, and intangible factors, such as happiness" (p.15). While analysing the GNH Index, Ura et al. (2012) found that Bhutan has based GNH on five core values depicting a holistic, balanced, collective, sustainable and equitable nation. Despite such commendable efforts, little evidence is available for how individual organisations can implement the above-mentioned core values - it is not immediately possible to know the operational plan at the organisational level or whether employees know exactly what their roles and expectations should be when discussing such values or initiatives.

So far, we have drawn attention to the uses of GNH and its weaknesses. More recent evidence from economic literature has focussed attention on the strengths of GNP (Mankiw, 2018) as an improved approach to measuring national success. Like the GNH, the GNP concept, developed in the 1930s, has also faced a number of challenges, as it was mainly an outcome of the Great Depression (Breene, 2016). Though instrumental in measuring the economic growth for the past 80 years, it is now considered as a tool with limitations by the United Nations (2013). Simon Kuznets, the creator of modern GNP, cautioned nations to not apply this tool to measure the nation's welfare and not to consider GNP as a sole instrument to measure nation's growth (Galbraith and Kum, 2003; Morrisson and Murtin, 2013; Sulkowski and White, 2016). The economic strengths of the GNP and GDP remain in the economic literature; however, these tools have limited ability in predicting down-turns and societal well-being. For example, it was not possible to predict the 2008 recession through the lenses of the GDP/GNP measures and most part of the world went through a severe recession causing living conditions to decrease. To strengthen the national tools, incorporating happiness into the organisational success framework instead of only financial metrics might provide a more realistic outcome.

Currently, the governments of Eastern, as well as Western nations are embracing the measurement of social well-being (in the form of happiness) and catching up with Bhutan's philosophy and practice of implementing GNH Index. Much earlier on, Dixon (2006) proposed that countries include intangible measures associated with happiness, so that important parameters are measured and then managed more effectively. Since 2006, a number of countries have started several initiatives in an attempt to measure and manage happiness. In the West, the USA created a "Key national indicator system"; French Government acknowledged to bring "an end to GDP fetishism" but have performed minimally in keeping the citizens happy (Senik, 2014). Along similar lines, the UK 
Government has started collecting happiness surveys a few years ago to help understand the level of happiness among its citizens (Sulkowski and White, 2016). A step further elsewhere in the global initiative on happiness has seen the UAE establish a new ministry called the Ministry of Happiness in 2016 to help provide policy and process on happiness initiatives among citizens and organisations. This makes the UAE a leader in the Middle East in terms of formulation of programmes that are lauded by global advocates. Though Bhutan has held its place in the Far East and continues in guiding the world to measure happiness, evidence suggests that its influence on neighbouring China to prioritise employee happiness has largely had minimal effect as China's happiness index remains at the 72nd position among the current 140 countries sampled.

Over the past few years and after the announcement by The United Nation's (UN) in 2013, advising countries to commemorate the 20th March as the International Day of Happiness, several countries have started to incorporate measures such as GNH in their national statistics (United Nations, 2013). Though several countries embraced the initiative, calls have been made by experts to consider explanatory factors such as GDP per capita, the social support, healthy life expectancy, freedom to make life choices, generosity and perception of corruption in the happiness ranking of countries (Helliwell et al., 2016, 2017).

\section{Discussion and the case for happiness in the UAE}

What we know about happiness in complex organisations in the UAE is largely based on derivatives from national statistics and international reports and less on academic research. As a country that is at the fore-front of happiness initiatives particularly in the GCC region, it is imperative that we academics explore the ways organisations' contributions can support this vision of the UAE. We hypothesise that the success of the UAE so far in its achievement of happiness can become even more sustainable, if studies on employee happiness increase and helpful practices are recommended to the happiness framework.

The achievements so far in making Dubai a smart city have been accounted for in the recent work by Zakzak and Salem (2019). Such initiatives towards making the entire UAE nation a happy one is commendable but requires additional research to help integrate the cultural diversity of the workforce as an important part of the variables that make the country's efforts sustainable. Although a young country and having been founded only in 1971, the vision of the UAE's leadership is to ensure that the nation is amongst the Top 5 happiest countries by the year 2021 (Happiness Agenda, 2018; Helliwell et al., 2017). In line with this ambition, organisations have embedded the concepts of positivity and happiness in their strategic plans and day-to-day operations since the establishment of The Minister of State of Happiness and Wellbeing position (Happiness Agenda, 2018). The Federal authority for HR in UAE implemented plans to increase happiness level at work (FAHR News, 2017) and as a result UAE's ranking jumped to 21st in the World Happiness Report (Helliwell et al., 2017). Despite the efforts, the dominance of expatriate population in UAE pose a challenge to achieving the national agenda of becoming the happiest country (Helliwell et al., 2012). A decade ago, Al-Waqfi and Forstenlechner (2010) observed that job insecurity, stress to earn more and residing on work permits are the common reasons for UAE's expatriates to feel unhappy. The above-mentioned variables are common to countries that depend on foreign labour; therefore, it becomes imperative to understand the role of these variables in the operations of complex organisations on one hand and how such complexities influence the promotion of happiness values at workplace in the current decade.

From the earlier information, the agenda for the future is clear however the gaps in the literature require filling through further research. In particular, two issues arose in the literature: definitional inconsistencies and exclusion of micro measurement efforts. While
Meaning of
"employee
happiness" 
RAMJ

14,2

finding a solution to the definitional problem is exclusively an academic activity, a flaw in the current literature is the focus on macro variables, which directly affects the accuracy of happiness measures and subsequent interventions that organisations can put in place. Specifically, as the literature provides no clear direction on what exactly constitutes happiness both in terms of its definition and metrics used in measuring happiness in organisations, we can hardly conclude that employees and employers expectations are met. Though the PERMA model has exemplary elements (Lambert D'raven and Pasha-Zaidi, 2016) that corporates can refer to for happiness policy formulation, it appears that employees could be aiming for a completely different happiness targets whereas their employers might be heading in a completely different direction. The problem of the happiness construct being mis-defined straddles across several institutions and global organisations, as can be seen in the earlier section; however, more needs to be done in terms of happiness research within the field of HR and management, particularly at a time when cross-cultural integration is at its highest across the world (Mullins, 2010; Hofstede Insights, 2018). In the management literature, a lot has been written on engagement, motivation and job satisfaction, which could potentially overlap with happiness theory, including the psychological model created by Seligman (2011). As per the popular PERMA model put forward by Seligman (2011), we need to approach the measure of happiness in general through a somewhat scientific method; however, happiness is a psychological disposition of the individuals pleasure or satisfaction, which can hardly be subjected to a positivist experiment within the laboratory environment. As a phenomenon, hardly generalisable, it is probably better to obtain information from employees through a selfreporting system that allows for the individuals to make sense of their own individualised definition and experience of happiness, as such an approach will be in line with the models currently used in the UAE but provide a corporate level data throughout the country and the region. Through this approach we can arrive at a much better understanding of what happiness is at both the individual and aggregate levels.

\section{Conclusion and scope for future research}

Using a quasi-literature review, we have collated and explored different definitions of happiness while at the same time looking at the evidence on happiness measurement framework from a selected number of countries and research organisations. We did this at the backdrop of the happiness initiatives in the UAE, which has a number of large organisations that are categorised as complex because of their inclination to recruit and manage diverse employees from all over the world. Though we discover that a number of existing models are available to the corporate world, the confusion that arises when employees and employers do not share a common definition of happiness cannot easily be eradicated through the continuous production of academic jargons and scientific research but it is recommended that employees define happiness from their own personal experience and motives stand point. As this level of scholarly exploration of happiness is currently missing, recommendation to engage more in research related to employee happiness has been made as follows:

- First, for future research, it is imperative to explore new ways of defining happiness within the discourse of complex cultural organisations while at the same time explaining the link between micro and macro measures. The conventional models such as the PERMA model and the World Happiness Index or the World Happiness Report have to be studied more closely, so that a more comprehensive fit within the management/HR discourse can be determined.

- Second, it is important that future research looks at the specific micro variables that could negatively impact on happiness initiatives in the UAE. For example, 
researchers can focus on the effect of job security and the potential impact on current levels of happiness.

- Third, if happiness is a relative concept such that what makes one person happy is different from another employee's perception of happiness then should there be a more rigorous evaluation of what we really mean by happiness? In this context, it is recommended that future research revaluates the current measurement tools mentioned earlier in this paper, so that a much better inclusive tool is developed for gauging employee/organisational happiness.

\section{Limitations}

This research uses a limited number of sources to explore definitional inconsistencies and to explain what we really mean by happiness in complex organisations. This provides a constraint on any conclusions that might derive from this research.

In parts of the paper, authors used opinions and personal interpretation of happiness programmes and their effectiveness. This means that organisations and allied entities should apply any recommendations with caution, as they would with any non-empirical research.

\section{References}

Adam, J.S. (1965), "Inequality in social exchange”, Advanced Experimental Psychology, Vol. 62 No. 1, pp. 335-343.

Al-Waqfi, M. and Forstenlechner, I. (2010), "Stereotyping of citizens in an expatriate-dominated labour market: implications for workforce localisation policy", Employee Relations, Vol. 32 No. 4, pp. 364-381, available at: https://doi.org/10.1108/01425451011051596

Anitha, J. (2014), "Determinants of employee engagement and their impact on employee performance", International Journal of Productivity and Performance Management, Vol. 63 No. 3, pp. 308-323, available at: https://doi.org/10.1108/IJPPM-01-2013-0008

Attridge, M. (2009), "Measuring and managing employee work engagement: a review of the research and business literature", Journal of Workplace Behavioral Health, Vol. 24 No. 4, pp. 383-398, available at: https://doi.org/10.1080/15555240903188398

Baddah, A. (2016), "The direction of change management in United Arab Emirates", International Journal of Business and Management, Vol. 11 No. 9, p. 126, available at: https://doi.org/10.5539/ ijbm.v11n9p126

Bassett-Jones, N. and Lloyd, G.C. (2005), "Does Herzberg's motivation theory have staying power?”, Journal of Management Development, Vol. 24 No. 10, pp. 929-943, available at: https://doi.org/ $10.1108 / 02621710510627064$

Benuyenah, V. and Pandya, B. (2020), "Measuring employee happiness in the UAE - integrating organisational data into the national statistics", International Review of Management and Marketing, Vol. 10 No. 3, pp. 83-92, available at: https://doi.org/10.32479/irmm.9698

Breene, K. (2016), These Are the World's Happiest Countries. But Who Measures Them and How?, World Economic Forum Cologny.

Burdbar Khan, M. and Nisar Sheikh, N. (2012), "Human resource development, motivation and Islam", Journal of Management Development, Vol. 31 No. 10, pp. 1021-1034, available at: https://doi.org/ $10.1108 / 02621711211281807$

Cascio, W.F. (2012), "Methodological issues in international HR management research", The International Journal of Human Resource Management, Vol. 23 No. 12, pp. 2532-2545, available at: https://doi.org/10.1080/09585192.2011.561242 
RAMJ

14,2

Cooksey, R.W. (2003), "Learnership in complex organisational textures", Leadership and Organization Development Journal, Vol. 24 No. 4, pp. 204-214, available at: https://doi.org/10.1108/ 01437730310478075

Critten, P. (2016), "A radical agenda for enabling organisation transformation through work-applied learning”, Journal of Work-Applied Management Iss, Vol. 8 No. 1, pp. 65-78, available at: https:// doi.org/10.1108/JWAM-05-2016-0006

Delle Fave, A., Brdar, I., Wissing, M.P., Araujo, U., Castro Solano, A., Freire, T., Hernández-Pozo, M.D.R., Jose, P., Martos, T., Nafstad, H.E., Nakamura, J., Singh, K. and Soosai-Nathan, L. (2016), "Lay definitions of happiness across nations: the primacy of inner harmony and relational connectedness", Frontiers in Psychology, Vol. 7, available at: https://doi.org/10.3389/fpsyg.2016.00030

Dixon, F. (2006), "Gross national happiness: measuring what matters", Reflections, Vol. 7 No. 3, pp. $15-24$.

Dong, K. and Liu, Y. (2010), "Cross-cultural management in China", Cross Cultural Management: An International Journal, Vol. 17 No. 3, pp. 223-243, available at: https://doi.org/10.1108/13527601011068333

Eatough, V. and Smith, J. (2010), "Interpretative phenomenological analysis", in Willig, C. and StaintonRogers, W. (Eds), The SAGE Handbook of Qualitative Research in Psychology, SAGE Publications, London, pp. 179-194, doi: 10.4135/9781848607927.n11.

FAHR News (2017), "Federal authority for government human resources", available at: www.fahr.gov. ae/en/news/22/5/2017/fahr-launches-employee-wellness-guidance-framework-in-the-federalgovernment.aspx (accessed 12 November 2018)

Fisher, C.D. (2010), "Happiness at work", International Journal of Management Reviews, Vol. 12 No. 4, pp. 384-412, available at: https://doi.org/10.1111/j.1468-2370.2009.00270.x

Galbraith, J.K. and Kum, H. (2003), "Inequality and economic growth: a global view based on measures of pay”, CESifo Economic Studies, Vol. 49 No. 4, pp. 527-556.

Happiness Agenda (2018), "Happiness agenda", available at: https://http://en.happinessagenda.ae/ \#overview, (accessed 26 May 2020).

Helliwell, J., Layard, R. and Sachs, J. (2012), World Happiness Report 2012, UN Sustainable Development Solutions Network. New York, NY.

Helliwell, J., Layard, R. and Sachs, J. (2016), World Happiness Report 2016, UN Sustainable Development Solutions Network. New York, NY.

Helliwell, J., Layard, R. and Sachs, J. (2017), World Happiness Report 2017, UN Sustainable Development Solutions Network. New York, NY.

Herzberg, F. (1959), The Motivation to Work, Wiley, New York, NY.

Hofstede Insights (2018). "Country comparison - Hofstede insights", available at: www.hofstedeinsights.com/country-comparison/thailand/ (accessed 25 May 2018).

Horwitz, F. (2017), "Culture in Angola: insights for human resources management", Cross Cultural Management, Vol. 45 No. 19, pp. 2853-2862, available at: https://doi.org/10.1108/CCM-02-2013-0036

Humphries, S.A. and Whelan, C. (2017), "National culture and corporate governance codes", Corporate Governance: The International Journal of Business in Society, Vol. 17 No. 1, pp. 152-163, doi: 10.1108/CG-06-2016-0127.

Jassawalla, A., Truglia, C. and Garvey, J. (2004), "Cross-cultural conflict and expatriate manager adjustment: an exploratory study", Management Decision, Vol. 42 No. 7, pp. 837-849, available at: https://doi.org/10.1108/00251740410550916

Jiao, C., Richards, D.A. and Zhang, K. (2011), "Leadership and organizational citizenship behavior: OCBspecific meanings as mediators", Journal of Business and Psychology, Vol. 26 No. 1, pp. 11-25, available at: https://doi.org/10.1007/s10869-010-9168-3

Kumar, V. and Pansari, A. (2015), "Measuring the benefits of employee engagement", MIT Sloan Management Review, Vol. 56 No. 4, pp. 67-72, doi: 10.1111/j.1754-9434.2007.0002.x 
Lambert, E.G., Hogan, N.L., Barton, S.M. and Clarke, A.W. (2002), "Satisfied correctional staff: a review of the literature on the correlates of correctional staff job satisfaction", Criminal Justice and Behavior, Vol. 29 No. 2, pp. 115-143.

Lambert D'raven, L. and Pasha-Zaidi, N. (2016), "Using the PERMA model in the United Arab Emirates", Social Indicators Research, Vol. 125 No. 3, pp. 905-933, doi: 10.1007/s11205-0150866-0.

Lawrie, G., Abdullah, N.A., Bragg, C. and Varlet, G. (2016), "Multi-level strategic alignment within a complex organisation", Journal of Modelling in Management, Vol. 11 No. 4, pp. 889-910, available at: https://doi.org/10.1108/JM2-11-2014-0085

McClelland, D.C. (1984), “Centennial psychology series”, Motives, Personality, and Society: Selected Papers, Praeger Publishers, Westport, CT.

Mankiw, N.G. (2018), Principles of Economics, 8th ed., Cengage Learning Boston.

Mangai, M.S. and De Vries, M.S. (2018), "Co-production as deep engagement", International Journal of Public Sector Management, Vol. 31 No. 1, pp. 81-96, available at: https://doi.org/10.1108/IJPSM03-2017-0084

Maslow, A.H. (1954), Motivation and Personality, Harper and Row, New York, NY.

Mikkelsen, E.N. and Clegg, S. (2017), "Conceptions of conflict in organizational conflict research: toward critical reflexivity”, Journal of Management Inquiry, Vol. 28 No. 2, doi: 10.1177/1056492617716774.

Morrisson, C. and Murtin, F. (2013), "The Kuznets curve of human capital inequality: 1870-2010", The Journal of Economic Inequality, Vol. 11 No. 3, pp. 283-301, available at: http://dx.doi.org.ezproxy. hct.ac.ae/10.1007/s10888-012-9227-2

Mullins, L.J. (2010), Management and Organisational Behaviour, 9th Edition: Financial Times Prentice, Harlow. ISBN9780273724087 0273724088.

Okulicz-Kozaryn, A. (2016), "Happiness research for public policy and administration”, Transforming Government: People, Process and Policy, Vol. 10 No. 2, pp. 196-211, available at: https://doi.org/ 10.1108/TG-07-2015-0030

Parackal, M. (2016), "A global happiness scale for measuring wellbeing: a test of immunity against hedonism”, Journal of Happiness Studies, Vol. 17 No. 4, pp. 1529-1545, available at: http://dx.doi. org.ezproxy.hct.ac.ae/10.1007/s10902-015-9657-1

Petticrew, M. and Roberts, H. (2008), "Systematic reviews - do they 'work' in informing decisionmaking around health inequalities?”, Health Economics, Policy and Law, Vol. 3 No. 2, pp. 197-211, available at: https://doi.org/10.1017/S1744133108004453

Powell, L. and Tilt, C. (2017), "The examination of power and politics in a conservation organisation", Accounting, Auditing and Accountability Joumal, Vol. 30 No. 3, pp. 482-509, doi: 10.1108/AAAJ-01-2015-1933.

Rahman, U.U., Rehman, C.A., Imran, M.K. and Aslam, U. (2017), "Does team orientation matter? Linking work engagement and relational psychological contract with performance", Journal of Management Development, Vol. 36 No. 9, pp. 1102-1113, available at: https://doi.org/10.1108/ JMD-10-2016-0204

Salas-Vallina, A., López-Cabrales, Á., Alegre, J. and Fernández, R. (2017), "On the road to happiness at work (HAW)", Personnel Review, Vol. 46 No. 2, pp. 314-338, available at: https://doi.org/10.1108/ PR-06-2015-0186

Seligman, M.E.P. (2011), Flourish: A Visionary New Understanding of Happiness and Well-Being, Free Press, New York, NY.

Senik, C. (2014), "The French unhappiness puzzle: the cultural dimension of happiness", Journal of Economic Behavior and Organization, Vol. 106, pp. 379-401, available at: https://doi.org/10.1016/ j.jebo.2014.05.010

Sithey, G., Thow, A.-M. and Li, M. (2015), “Gross national happiness and health: lessons from Bhutan”, Bulletin of the World Health Organization, Vol. 93 No. 8, pp. 514. 
RAMJ

14,2

180

Smith, J.A. (2010), "Interpretative phenomenological analysis: a reply to Amedeo Giorgi", Existential Analysis, Vol. 21 No. 2, p. 186.

Solansky, S.T., Singh, B. and Huang, S. (2014), "Individual perceptions of task conflict and relationship conflict", Negotiation and Conflict Management Research, Vol. 7 No. 2, pp. 83-98, available at: https://doi.org/10.1111/ncmr.12027

Sulkowski, A. and White, D.S. (2016), "A happiness Kuznets curve? Using model-based cluster analysis to group countries based on happiness, development, income, and carbon emissions", Environment, Development and Sustainability, Vol. 18 No. 4, pp. 1095-1111, available at: http:// dx.doi.org.ezproxy.hct.ac.ae/10.1007/s10668-015-9689-z

Tella, R. and MacCulloch, R. (2006), "Some uses of happiness data in economics", Journal of Economic Perspectives, Vol. 20 No. 1, pp. 25-46, available at: https://doi.org/10.1257/jel.48.2.281

The World Bank (2018), "Data bank", available at: http://databank.worldbank.org/data/home.aspx, Accessed: 1/12/2018

Thorne, M.L. (2000), "Interpreting corporate transformation through failure", Management Decision, Vol. 38 No. 5, pp. 305-314, available at: https://doi.org/10.1108/00251740010340481

United Nations (2013), "UN news - on first international day of happiness, ban calls for inclusive human development”, UN News Service Section, available at: www.un.org/apps/news/story.asp? NewsID=44430\#.WngJenyYPIV

Ura, K., Alkire, S., Zangmo, T. and Wangdi, K. (2012), An Extensive Analysis of GNH Index, The Centre for Bhutan Studies, Thimphu.

Veenhoven, R. (2009), "How do we assess how happy we are? Tenets, implications and tenability of three theories", Happiness, Economics and Politics: Towards a Multi-Disciplinary Approach, October, 45-69, available at: www2.eur.nl/fsw/research/veenhoven/Pub2000s/2009a-full.pdf

Vroom, V.H. (1964), Work and Motivation, Wiley. New York, NY.

Zakzak, L. and Salem, F. (2019), "Building a happy city - the case of smart Dubai's happiness agenda", Future Governments (Actions and Insights - Middle East North Africa, Vol. 7), Emerald Publishing, pp. 271-301, available at: https://doi.org/10.1108/S2048-757620190000007015

\section{Further reading}

Helliwell, J., Layard, R. and Sachs, J. (2013), World Happiness Report 2013, UN Sustainable Development Solutions Network, New York, NY.

Helliwell, J., Layard, R. and Sachs, J. (2015), World Happiness Report 2015, UN Sustainable Development Solutions Network, New York, NY.

\section{About the authors}

Vic Benuyenah's research expertise includes labour market inefficiencies, management decision and conflict theory. He writes on labour economics and psychological issues in international business organisations. Dr. Benuyenah teaches economics, and HRM at Dubai Women's College, UAE. Vic Benuyenah is the corresponding author and can be contacted at: vbenuy01@gmail.com

Bharti Pandya is an expert in organisational theory and practice. She currently teaches organisational behavior and commercial law among other management subjects.

For instructions on how to order reprints of this article, please visit our website:

www.emeraldgrouppublishing.com/licensing/reprints.htm

Or contact us for further details: permissions@emeraldinsight.com 